\title{
Evaluation of Therapeutic Potential of Phenoxodiol, a Novel Isoflavone Analog, in Renal Cancer Cells
}

\author{
MAKOTO ISONO, AKINORI SATO, TAKAKO ASANO, KAZUKI OKUBO and TOMOHIKO ASANO
}

Department of Urology, National Defense Medical College, Tokorozawa, Japan

\begin{abstract}
Background/Aim: In the present study, the antineoplastic activity and mechanism of action of phenoxodiol, a novel isoflavone analog, was investigated in renal cancer cells. Materials and Methods: A panel of renal cancer cells (769-P, 786-O, Caki-2) was treated with phenoxodiol in vitro, and the efficacy of treatment was evaluated. Results: MTS assay results showed that phenoxodiol decreased renal cancer viability in a dosedependent manner. In addition, it inhibited colony formation significantly and perturbed the cell cycle. Treatment with phenoxodiol increased the number of annexin-V-positive cells as well as the expression of cleaved poly ADP ribose polymerase, demonstrating that phenoxodiol induced apoptosis in renal cancer cells. Phenoxodiol also inhibited Akt pathway via dephosphorylation of Akt. Conclusion: Phenoxodiol inhibited Akt pathway and induced apoptosis of renal cancer cells. The present study provides a theoretical basis for future development of a novel therapy effective against renal cancer.
\end{abstract}

Renal cell carcinoma (RCC) is a major cause of morbidity and mortality worldwide, and it accounts for $3 \%$ of all adult cancer cases (1). In patients with RCC, $30 \%$ have metastatic disease at the time of diagnosis, while another $20-30 \%$ develop metastases following surgery (2). However, the efficacy of systemic treatment in patients with metastatic RCC is limited. Although the treatment options available for metastatic RCC have recently improved owing to the clinical development of targeting agents, including tyrosine kinase inhibitors (3), metastatic RCC has a poor prognosis. Despite the improved prognosis of patients with RCC by these treatment modalities, RCC is associated with development of resistance and complete responses remain an exception

Correspondence to: Makoto Isono, Department of Urology, National Defense Medical College, 3-2 Namiki, Tokorozawa, Saitama, Japan. Tel: +81 429951676, Fax: +81 429965210, e-mail: mktisn@hotmail.com

Key Words: Phenoxodiol, renal cancer, Akt, c-FLIP.
(4). Therefore, studies aiming to identify a novel therapeutic agent to treat patients with metastatic RCC are required.

Isoflavonoids have received significant attention owing to their potential anti-carcinogenic and anti-proliferative effects (5). Their anti-tumor effects have been observed in renal cancer, and higher intake of flavonoids have been reported to be inversely related to the risk of renal cancer (6). They are dietary nutrients that are known to possess diverse functional roles in animal and human cells. They have also been shown to be effective in inducing mitotic arrest and apoptosis in many cancer cells (7). Phenoxodiol is a synthetic isoflav-3-ene metabolite that is a natural intermediate in the metabolism of daidzein to equol (8). It has been demonstrated that phenoxodiol exerts a range of anti-tumor effects in vitro and in vivo $(9,10)$, including inhibitory effects on angiogenic mediator production and inhibitory effects on inflammation $(11,12)$. However, the underlying mechanism of action has not been fully elucidated. It is considered to show pleotropic effects such as inhibition of tyrosine kinases and topoisomerase II, and $\mathrm{X}$-linked inhibition of apoptosis (XIAP) $(10,13,14)$. It is also capable of enhancing chemo-sensitivity in cancer cells through inhibiting XIAP $(15,16)$. It has been demonstrated that phenoxodiol administration during cisplatin-based chemotherapy against platinum-refractory/resistant epithelial ovarian, fallopian tube, or primary peritoneal cancer improves clinical outcomes, suggesting that phenoxodiol may be an effective adjuvant in the treatment of cancer (17).

The present study aimed to investigate the in vitro antineoplastic activity of phenoxodiol and to elucidate its mechanism of action in renal cancer cells. To our knowledge, this is the first detailed preclinical characterization of the novel isoflavone analog phenoxodiol in renal cancer.

\section{Materials and Methods}

Cell culture and treatment. Experiments were performed in the human renal cancer cell lines 769-P, 786-O, and Caki-2 (obtained from the American Type Culture Collection, Rockville, MD, USA). Renal cancer cells were routinely cultured in RPMI or McCoy's 5A medium (depending on the cell line) supplemented with $10 \%$ fetal bovine serum and $1 \%$ penicillin/streptomycin (Invitrogen, Carlsbad, 
CA, USA) at $37^{\circ} \mathrm{C}$ in a humidified atmosphere with $5 \% \mathrm{CO}_{2}$. The experiments were performed $24 \mathrm{~h}$ after cell seeding with a single dose of phenoxodiol (purchased from Selleck Chemicals, Houston, TX, USA). Phenoxodiol was dissolved in dimethyl sulfoxide (DMSO) and was stored at $-70^{\circ} \mathrm{C}$ until use.

Determination of mean inhibitory concentrations and viability. The mean inhibitory concentrations $\left(\mathrm{IC}_{50}\right)$ and viability after $72-\mathrm{h}$ treatment were measured by MTS assay (CellTiter 96 Aqueous kit; Promega, Madison, WI, USA), according to the manufacturer's protocol. The cells were seeded at a density of $3 \times 10^{3}$ cells per well on 96-well culture plates, allowed to attach for $24 \mathrm{~h}$, and treated in three independent experiments with 5-40 $\mu \mathrm{M}$ phenoxodiol.

Colony formation assay and Giemsa staining. Colony formation assay was performed after 24, 48 and $72 \mathrm{~h}$ of phenoxodiol treatment. The cells were plated in a 6 -well plate at a density of $3 \times 10^{3}$ cells per plate. Colonies formed after 10 days were washed with phosphate-buffered saline, fixed in $100 \%$ methanol, and stained with Giemsa's solution (Muto, Tokyo, Japan).

Flow cytometry. Flow cytometry was performed to evaluate cell cycle changes and apoptosis. Briefly, $7.5 \times 10^{4}$ cells were seeded in a 6-well culture plate 1 day prior to treatment with phenoxodiol. Cell cycle analysis was performed after 24,48 and $72 \mathrm{~h}$ of treatment. The attached cells and cells in the supernatant were resuspended in citrate buffer and stained with propidium iodide. For annexin $\mathrm{V}$ assay, the cells were stained with annexin $\mathrm{V}$ and 7-amino-actinomycin D (7-AAD) according to the manufacturer's protocol (Beckman Coulter, Marseille, France) and analyzed by flow cytometry using CellQuest Pro software (BD Biosciences, San Jose, CA, USA).

Western blot analysis. For western blotting, the cells were maintained under the indicated conditions for 24,48 or $72 \mathrm{~h}$. Total protein was extracted for $30 \mathrm{~min}$ on ice by cell lysis in a RIPA-buffer containing $150 \mathrm{mM} \mathrm{NaCl}, 1 \%$ Triton X-100, $0.5 \%$ deoxycholate, $1 \%$ Nonidet P-40, $0.1 \%$ sodium dodecyl sulfate (SDS), $1 \mathrm{mM}$ EDTA, $50 \mathrm{mM}$ Tris (pH 7.6), and $10 \mu \mathrm{l} / \mathrm{ml}$ protease inhibitor cocktail (Sigma Aldrich St. Louis, MO, USA). Protein concentrations were determined by BCA protein assay (Thermo Scientific, Rockford, IL, USA). Equal amounts of proteins were separated by SDS-polyacrylamide gel electrophoresis and transferred to nitrocellulose membranes. The primary antibodies used were anti-cyclin A, -B1, -D1, -E (1:400), anti-cyclin-dependent kinase (CDK) 4 (1:400), anti-p21 CIP1, antiFLIP (1:400) (Santa Cruz Biotechnology, Santa Cruz, CA, USA), anti-cleaved poly [ADP-ribose] polymerase (PARP) $(1: 1,000)$, antiAkt $(1: 1,000)$, anti-phosphorylated Akt (p-Akt) $(1: 1,000)$ (Cell Signaling Technology, Danvers, MA, USA), and anti-actin $(1: 3,000$, Millipore, Billerica, MA, USA) as loading controls. Secondary antibodies were horseradish peroxidase (HRP)-conjugated goat-antimouse antibody and HRP-conjugated goat-anti-rabbit antibody (1:6000, Bio-Rad, Hercules, CA, USA) for $1 \mathrm{~h}$ at RT. The bands were visualized using chemiluminescence with the ECL Plus system (GE Healthcare, Wauwatosa, WI, USA), according to the manufacturer's instructions.

Statistical analysis. Data are presented as the mean \pm standard error of the mean of three independent experiments. $\mathrm{IC}_{50}$ values were approximated using CalcuSyn software (Biosoft, Cambridge, UK).

\section{Results}

Phenoxodiol significantly impacted proliferation, morphology, and clonogenicity of renal cancer cells. First, the $\mathrm{IC}_{50}$ values of phenoxodiol were determined in renal cancer cells (769-P, 786-O, and Caki-2). Treatment with phenoxodiol resulted in markedly reduced proliferation rate of the investigated renal cancer cells in a dose-dependent manner, with slight variations in $\mathrm{IC}_{50}$ values (range $\left.=19.9-28.8 \mu \mathrm{M}\right)$ (Figure 1A, Table I). To identify the potential mechanisms involved in the inhibition of proliferation and clonogenicity in renal cancer cells, the changes in cell morphology after phenoxodiol treatment were investigated (Figure 1B). The number of detached, shrunken cells, suggestive of induction of apoptosis, as well as the number of attached, enlarged, and vacant-looking cells, suggestive of senescent and/or necrotic cells, were increased by phenoxodiol treatment compared with the number of cells in the DMSO controls. Clonogenicity was impaired by phenoxodiol treatment in renal cancer cells, indicating that phenoxodiol efficiently inhibited long-term growth of renal cancer cells in vitro (Figure 1C).

Phenoxodiol perturbed cell-cycle distribution in renal cancer cells. Cell-cycle analysis by flow cytometry revealed profound disturbances of the cell cycle by phenoxodiol treatment in all the investigated cell lines (Figure 2A). After 72-h treatment, the cell cycle profiles became highly irregular, prohibiting proper quantification of cell cycle distribution. Notably, 72-h treatment with phenoxodiol increased the number of cells in the sub- $\mathrm{G}_{1}$ fraction. An explanation for these observations is disturbed and unequal distribution of DNA.

The changes in cell cycle profiles elicited by phenoxodiol were not reflected in accordance with the changes in the expression of cyclins in renal cancer cells (Figure 2B). However, the expression of CDK4 was reduced and induction of $\mathrm{p} 21^{\mathrm{CIP} 1}$, a classical marker of cell cycle arrest, was detected after 48 and $72 \mathrm{~h}$ of phenoxodiol treatment.

Phenoxodiol induces apoptosis of renal cancer cells. Next, the extent to which apoptosis contributed to cell death following phenoxodiol treatment was investigated. For the evaluation of apoptotic response, annexin $\mathrm{V}$ assay was conducted after 72$\mathrm{h}$ treatment of renal cancer cells with phenoxodiol. Annexin V/7AAD staining suggested a mixture of apoptotic and necrotic cell death, with a strong increase in early apoptotic and late apoptotic/necrotic cells and a slight increase in necrotic cells after phenoxodiol treatment, especially at higher concentrations (Figure 3A). Accordingly, efficient induction of apoptosis by phenoxodiol was evidenced by enhanced cleaved PARP detected by western blotting (Figure 3B).

Phenoxodiol inhibited c-FLIP expression and altered Akt phosphorylation status. Potential signaling pathways 

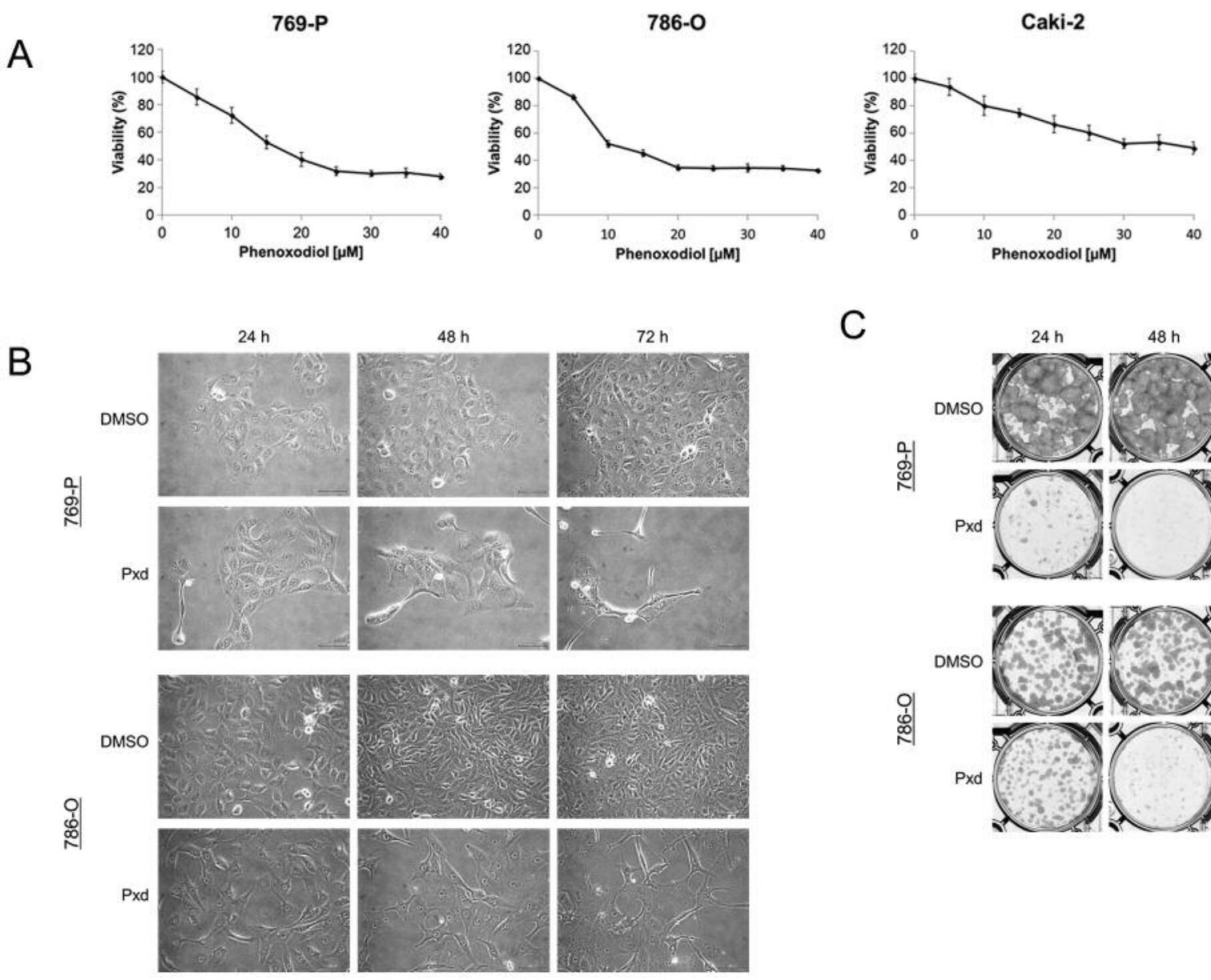

C

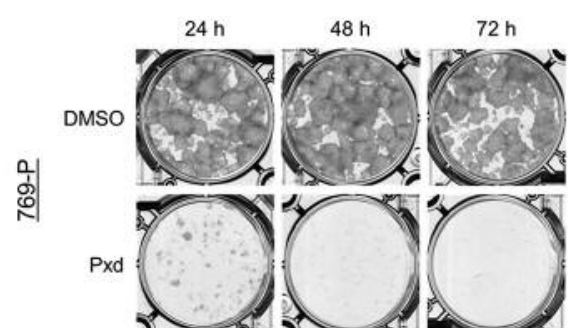

Figure 1. Phenoxodiol inhibited renal cancer cell growth in vitro. A: Renal cancer cells (769-P, 786-O, Caki-2) were treated with increasing amounts of phenoxodiol. Relative cell viability was measured by MTS assay (mean $\pm S D, n=6)$ after 72- $h$ treatment. B: Photomicrographs showing characteristic morphological changes in 769-P and 786-O cells treated with phenoxodiol $(24,48$, and 72 h). Scale bar=100 $\mu m$. C: Giemsa staining of grown colonies from renal cancer cells after 24-, 48-, and 72-h treatments compared to DMSO solvent control. Pxd stands for phenoxodiol. The concentration of phenoxodiol is each $I_{50}$ value.

underlying the anti-tumor activity of phenoxodiol in renal cancer cells were subsequently investigated. Cellular FLICE-like inhibitory protein (c-FLIP) is an important blocker of Fas pathway that competes with caspase-8/-10 for binding to the death-inducing signaling pathway (18). Accumulating evidence indicates that c-FLIP has an antiapoptotic role and is involved in chemotherapeutic drug resistance in various types of human cancers (19). It is possible that phenoxodiol increases the sensitivity of renal cancer cells to Fas-mediated apoptosis because of caspase activation associated with the removal of FLIP. Cell lysates were subjected to western blotting following incubation of cells for 24, 48 and $72 \mathrm{~h}$ in the presence or absence of phenoxodiol at each $\mathrm{IC}_{50}$ concentration (Figure 4A). Phenoxodiol decreased the expression of c-FLIPL and c-FLIPS in 769-P and 786-O cells.
Table I. Mean inhibitory concentrations $\left(I C_{50}\right)$ of phenoxodiol. After treatment of renal cancer cells with phenoxodiol for $72 h$, MTS assay was performed to assess cell viability.

Phenoxodiol

\begin{tabular}{lc}
\hline Cell line & $\mathrm{IC}_{50}(\mu \mathrm{M})$ \\
\hline $769-\mathrm{P}$ & 20.6 \\
$786-\mathrm{O}$ & 19.9 \\
Caki-2 & 28.8 \\
\hline
\end{tabular}

Previous studies have demonstrated that Akt regulates FLIP expression and blocks Fas-mediated apoptosis (20). The levels of p-Akt in all the investigated cells were decreased by phenoxodiol treatment in a time-dependent 
A

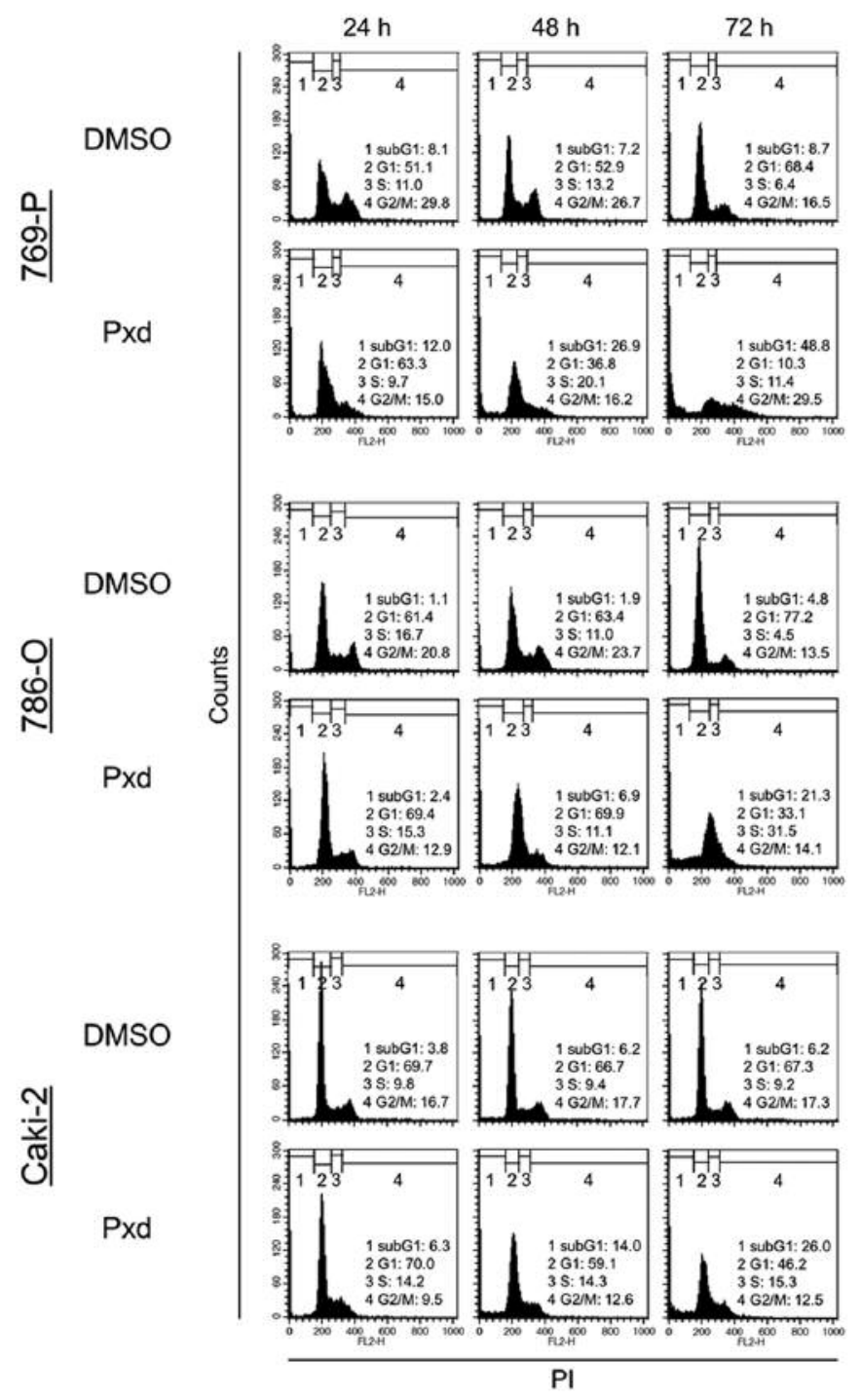

B

769-P

$786-\mathrm{O}$

Caki-2
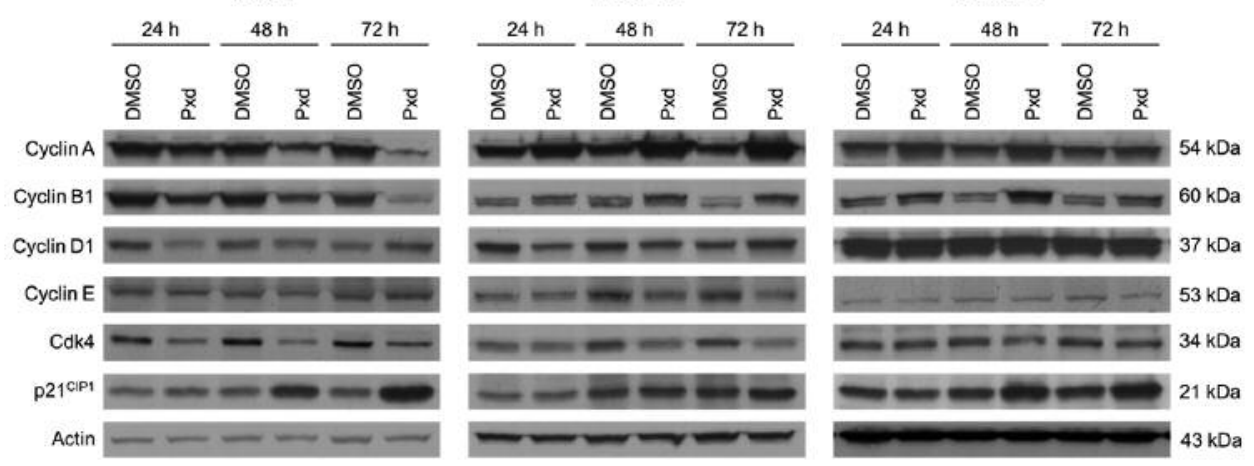

Figure 2. Phenoxodiol perturbed the cell cycle in renal cancer cells. A: Cell-cycle changes and number of apoptotic cells (as sub-G fraction) after phenoxodiol treatment in renal cancer cells were measured by cell-cycle analysis using flow cytometry. DMSO is the solvent control. Pxd stands for phenoxodiol. The concentration of phenoxodiol is each $I C_{50}$ value. B: Cyclins $(A, B 1, D 1, E), C D K 4$ and p21CIP1 protein expression levels following phenoxodiol treatment were quantified by western blot analysis relative to DMSO in renal cancer cells. Pxd stands for phenoxodiol. The concentration of phenoxodiol is each $I_{50}$ value. 
A

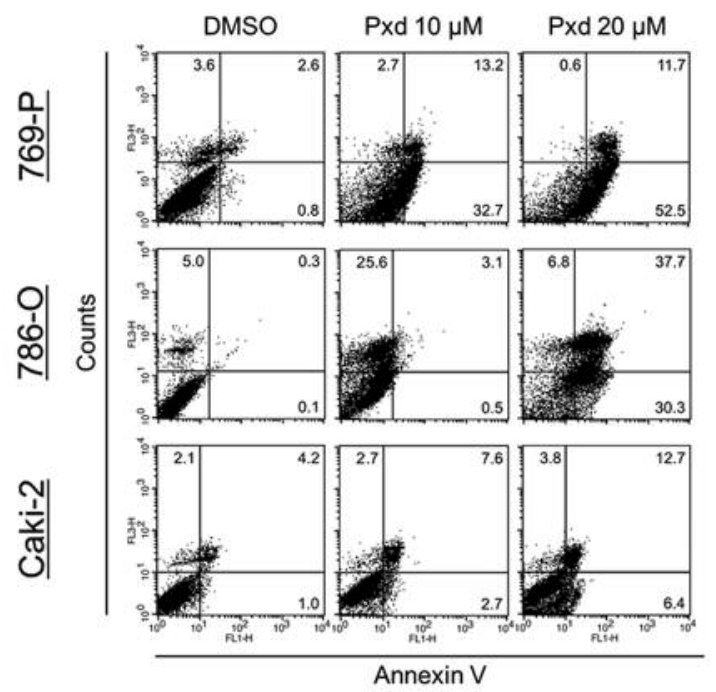

B
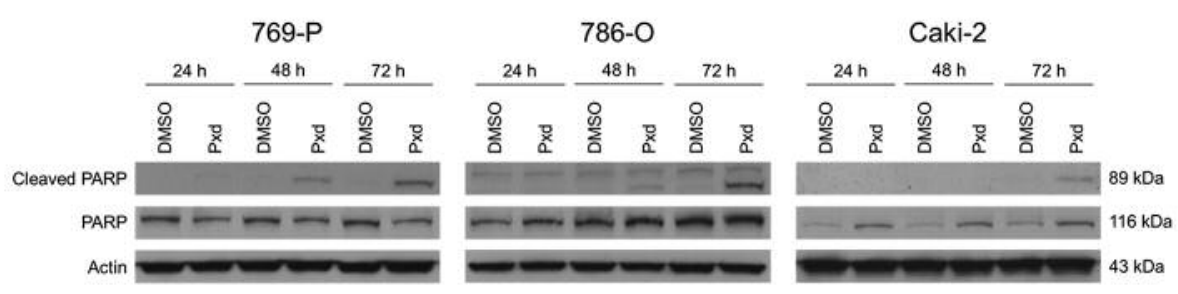

Figure 3. Phenoxodiol induced apoptosis in renal cancer cells. A: Annexin V assay. Cells were treated for 72 with phenoxodiol. Ten thousand cells were counted, and apoptotic cells were detected by annexin $V$ assay using flow cytometry. The inset in each graph shows the percentage of the cells. Representative results of flow cytometry are shown. B: Western blot analysis for cleaved poly(ADP-ribose) polymerase (PARP). The cells were treated for $72 \mathrm{~h}$ with phenoxodiol. Actin was used as the loading control. Pxd stands for phenoxodiol. The concentration of phenoxodiol is each IC 50 value. Representative blots are shown.

manner (Figure 4B). However, phenoxodiol had no discernible effect on the levels of Akt. Taken together, phenoxodiol induced apoptosis corresponding to a reduction in $\mathrm{p}$-Akt and c-FLIP expression.

\section{Discussion}

In this preclinical study, the suitability of the isoflavone analog phenoxodiol as a novel treatment modality in renal cancer cells was evaluated. Phenoxodiol significantly impaired proliferation of renal cancer cells and was efficacious in inhibiting clonogenic growth in vitro. The cytotoxic effect of phenoxodiol on renal cancer cells was characterized, although there were some differences in sensitivity probably due to phenotypic or genetic differences between the cell lines. This is a highly efficient drug inducing apoptosis in all the investigated renal cancer cells, possibly through regulatory effects on the Akt-FLIP pathway.
Clear cell carcinoma is the most common form of RCC (21). Around $80-90 \%$ of cases of clear cell RCC carry genetic variations of the von Hippel-Lindau tumor suppressor (VHL) and are associated with a hyperangiogenic state due to the overproduction of vascular endothelial growth factor $(22,23)$. However, the loss of VHL function alone is not sufficient for clear cell RCC initiation (24). The antiapoptotic effect of survival signals, such as those of the Akt pathway, promote cell proliferation over cell death. Akt signaling is usually activated through various mechanisms in clear cell RCC (25). The VHL and Akt pathways are closely connected and form a large signaling network contributing to clear cell RCC (26). Akt translocates to the nucleus where it may contribute to the regulation of transcription of genes mediating cell survival. One of the possible mechanisms by which Akt functions as a promoter of survival is through the induction of c-FLIP expression and blocking the extrinsic apoptotic pathway $(27,28)$. In the current study, phenoxodiol was shown to possess proapoptotic properties in renal cancer 

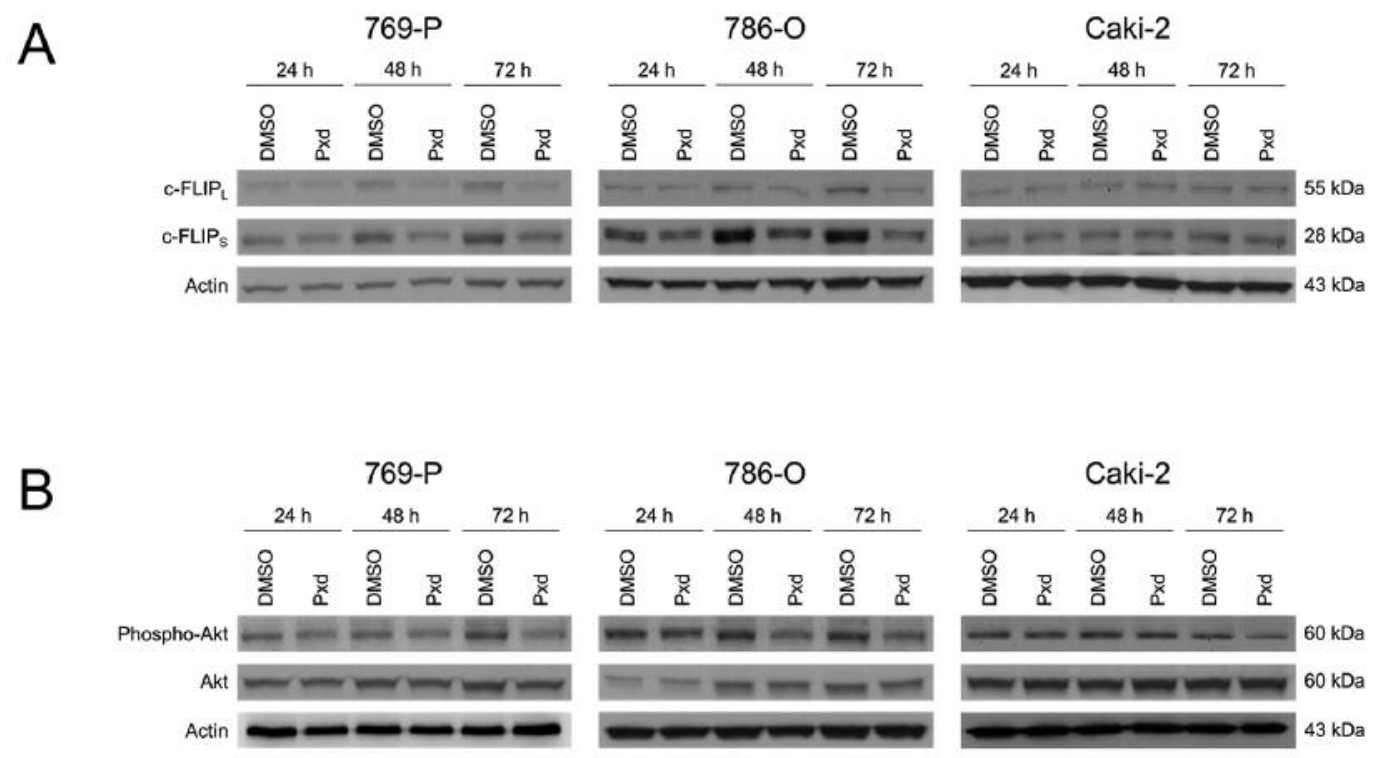

Figure 4. Phenoxodiol inhibited Cellular FLICE-like inhibitory protein (c-FLIP) expression and Akt pathway. A: Western blot analysis for c-FLIP. Whole-cell lysates from renal cancer cells treated with phenoxodiol for 24,48 , and $72 \mathrm{~h}$ were assayed. As a loading control, actin was used on each blot. Pxd stands for phenoxodiol. The concentration of phenoxodiol is each $I_{50}$ value. Representative blots are shown. B: Western blot analysis for Akt. Whole-cell lysates from renal cancer cells treated with phenoxodiol for 24, 48, and $72 \mathrm{~h}$ were assayed. As a loading control, actin was used on each blot. Pxd stands for phenoxodiol. The concentration of phenoxodiol is each $I_{50}$ value. Representative blots are shown.

cells. Tumor cells exposed to phenoxodiol exhibited distress almost immediately, accompanied by decreased expression of antiapoptotic factors Akt and c-FLIP. Thus, the effects of phenoxodiol are characterized by not only caspase activation, but also the status of antiapoptotic proteins.

Defects in apoptotic signaling in malignant cells contribute to drug resistance in various cancer types (29). Thus, targeting the factors regulating apoptosis represents a novel approach for the treatment of cancer cells. c-FLIP, a catalytically inactive caspase $8 /-10$ homolog, is involved in chemotherapeutic drug resistance in a wide range of human malignancies (19). Among 13 splice variants of c-FLIP, three forms can be detected at the protein level: c-FLIP ${ }_{L}, c-$ FLIP $_{S}$, and $c-$ FLIP $_{R}(30)$. Besides its function as an apoptosis modulator, c-FLIP exerts other cellular functions including increased cell proliferation and tumorigenesis (31). Moreover, high expression of c-FLIP is associated with short survival periods in patients with RCC (32). Therefore, the expression levels of c-FLIP may become a predictive biomarker for the prognosis of clinical outcome in patients with metastatic RCC. The apoptotic effect of phenoxodiol in renal cancer cells seems to be related to a decrease in the expression of c-FLIP. Increasing evidence supports the investigation of c-FLIP as a therapeutic target to restore apoptotic response in cancer cells. This is because the current understanding of c-FLIP action in normal cells supports the notion that c-FLIP-targeted cancer therapy will be well tolerated $(33,34)$.
Other mechanisms involved in the antineoplastic effect of phenoxodiol were investigated and results showed that phenoxodiol has the capacity to disturb cell cycle progression. Cell cycle arrest may occur due to the loss of the activity of CDKs (35). One of the mechanisms by which CDK inactivation occurs is via modulating the upstream pathways that govern the expression of cyclins, CDKs, or endogenous CDK inhibitor p21 (36). Several findings indicate that $\mathrm{p} 21^{\mathrm{CIP} 1}$ is involved in the control of DNA repair pathways, including homologous recombination (HR) (37). $\mathrm{p} 21^{\mathrm{CIP} 1}$ promotes HR by inhibiting CDKs, because increased CDK activity in the absence of $\mathrm{p} 21^{\mathrm{CIP} 1}$ is associated with elevated levels of DNA damage (38). It has previously been reported that phenoxodiol causes cell-cycle arrest at $\mathrm{G}_{1}$ owing to the loss of cdk2 activity by p53independent induction of $\mathrm{p} 21^{\mathrm{CIP} 1}$ (39). In the present study, the expression of $\mathrm{p}_{21}{ }^{\mathrm{CIP1}}$ was increased after 48 and $72 \mathrm{~h}$ of phenoxodiol treatment in all the investigated cell lines (Figure 2B), whereas cell cycle arrest was observed at different phases in each cell line. This observation suggests a role for $\mathrm{p} 21^{\mathrm{CIP} 1}$ in DNA repair in renal cancer cells. Cell cycle interference by phenoxodiol may occur through the inhibition of topoisomerase II (13).

One limitation of the present study was that the efficacy of phenoxodiol has not been evaluated in animal models. The next step toward application of phenoxodiol should be animal experiments evaluating side effects and determining 
the optimal dosage. However, a phase I clinical trial of phenoxodiol and pharmacokinetic study in humans were conducted in patients with solid tumors other than renal cancer, and no severe adverse events related to the medication were observed $(40,41)$. In future study, we aim to determine whether phenoxodiol shows efficacy with tolerable toxicity in patients with advanced renal cancer.

In conclusion, similar to results from previous preclinical and clinical studies investigating a range of cancers, the results of the present study suggest that phenoxodiol exerts a significant antineoplastic effect and can be a potential therapeutic agent for the treatment of renal carcinoma. Future clinical use of phenoxodiol for the treatment of RCC deserves further investigation.

\section{Conflicts of Interest}

None of the Authors have any conflicts of interest to disclose regarding this study.

\section{Acknowledgements}

The Authors would like to thank Editage (www.editage.jp) for English language editing.

\section{References}

1 Jemal A, Siegel R, Ward E, Hao Y, Xu J, Murray T and Thun MJ: Cancer statistics, 2008. CA Cancer J Clin 58(2): 71-96, 2008.

2 Bukowski RM: Prognostic factors for survival in metastatic renal cell carcinoma: Update, 2008. Cancer 115(10): S2273-S2281, 2009.

3 Posadas EM and Figlin RA: Systemic therapy in renal cell carcinoma: advancing paradigms. Oncology (Williston Park) 26(3): 290-301, 2012.

4 Motzer RJ, Hutson TE, Cella D, Reeves J, Hawkins R, Guo J, Nathan P, Staehler M, de Souza P, Merchan JR, Boleti E, Fife $\mathrm{K}$, Jin J, Jones R, Uemura H, De Giorgi U, Harmenberg U, Wang J, Sternberg CN, Deen K, McCann L, Hackshaw MD, Crescenzo R, Pandite LN and Choueiri TK: Pazopanib versus sunitinib in metastatic renal-cell carcinoma. N Engl J Med 369(8): 722-731, 2013.

5 Pavese JM, Farmer RL and Bergan RC: Inhibition of cancer cell invasion and metastasis by genistein. Cancer Metastasis Rev 29(3): 465-482, 2010.

6 Bosetti C, Rossi M, McLaughlin JK, Negri E, Talamini R, Lagiou P, Montella M, Ramazzotti V, Franceschi S and LaVecchia C: Flavonoids and the risk of renal cell carcinoma. Cancer Epidemiol Biomarkers Prev 16(1): 98-101, 2007.

7 Kandaswami C, Lee LT, Lee PP, Hwang JJ, Ke FC, Huang YT and Lee MT: The antitumor activities of flavonoids. In Vivo 19(5): 895-909, 2005.

8 Joannou G Kelly G, Reeder A, Waring M and Nelson C: A urinary profile study of dietary phytoestrogens. The identification and mode of metabolism of new isoflavonoids. $\mathbf{J}$ Steroid Biochem Mol Biol 54: 167-184, 1995.

9 Aguero MF, Venero M, Brown DM, Smulson ME and Espinoza LA: Phenoxodiol inhibits growth of metastatic prostate cancer cells. Prostate 70(11): 1211-1221, 2010.
10 Alvero AB, O’Malley D, Brown D, Kelly G, Garg M, Chen W, Rutherford T and Mor G: Molecular mechanism of phenoxodiolinduced apoptosis in ovarian carcinoma cells. Cancer 106(3): 599-608, 2006.

11 Gamble JR, Xia P, Hahn CN, Drew JJ, Drogemuller CJ, Brown $\mathrm{D}$ and Vadas MA: Phenoxodiol, an experimental anticancer drug, shows potent antiangiogenic properties in addition to its antitumour effects. Int J Cancer 118(10): 2412-2420, 2006.

12 Widyarini S, Spinks N, Husband AJ and Reeve VE: Isoflavonoid compounds from red clover (Trifolium pratense) protect from inflammation and immune suppression induced by UV radiation. Photochem Photobiol 74(3): 465-470, 2001.

13 Constantinou AI and Husband A: Phenoxodiol (2H-1benzopyran-7-0,1,3-(4-hydroxyphenyl)), a novel isoflavone derivative, inhibits DNA topoisomerase II by stabilizing the cleavable complex. Anticancer Res 22(5): 2581-2585, 2002.

14 Kluger HM, McCarthy MM, Alvero AB, Sznol M, Ariyan S, Camp RL, Rimm DL and Mor G: The X-linked inhibitor of apoptosis protein (XIAP) is up-regulated in metastatic melanoma, and XIAP cleavage by Phenoxodiol is associated with Carboplatin sensitization. J Transl Med 5: 6, 2007.

15 Kamsteeg M, Rutherford T, Sapi E, Hanczaruk B, Shahabi S, Flick M, Brown D and Mor G: Phenoxodiol - an isoflavone analog - induces apoptosis in chemoresistant ovarian cancer cells. Oncogene 22(17): 2611-2620, 2003.

16 Miyamoto M, Takano M, Aoyama T, Soyama H, Ishibashi H, Kato K, Iwahashi H, Takasaki K, Kuwahara M, Matuura H, Sakamoto T, Yoshikawa T and Furuya K: Phenoxodiol increases cisplatin sensitivity in ovarian clear cancer cells through XIAP down-regulation and autophagy inhibition. Anticancer Res 38(1): 301-306, 2018.

17 Kelly MG, Mor G, Husband A, O’Malley DM, Baker L, Azodi M, Schwartz PE and Rutherford TJ: Phase II evaluation of phenoxodiol in combination with cisplatin or paclitaxel in women with platinum/taxane-refractory/resistant epithelial ovarian, fallopian tube, or primary peritoneal cancers. Int $\mathbf{J}$ Gynecol Cancer 21(4): 633-639, 2011.

18 Safa AR, Day TW and Wu CH: Cellular FLICE-Like inhibitory protein (C-FLIP): a novel target for cancer therapy. Curr Cancer Drug Targets 8(1): 37-46, 2008.

19 Bagnoli M, Canevari S and Mezzanzanica D: Cellular FLICEinhibitory protein (c-FLIP) signalling: a key regulator of receptor-mediated apoptosis in physiologic context and in cancer. Int J Biochem Cell Biol 42(2): 210-213, 2010.

20 Rohn JL, Hueber AO, McCarthy NJ, Lyon D, Navarro P, Burgering BM and Evan GI: The opposing roles of the Akt and c-Myc signalling pathways in survival from CD95-mediated apoptosis. Oncogene 17(22): 2811-2818, 1998.

21 Keith B, Johnson RS and Simon MC: HIF1 $\alpha$ and HIF2 $\alpha$ : sibling rivalry in hypoxic tumour growth and progression. Nat Rev Cancer 12(1): 9-22, 2011.

22 Nickerson ML, Jaeger E, Shi Y, Durocher JA, Mahurkar S, Zaridze D, Matveev V, Janout V, Kollarova H, Bencko V, Navratilova M, Szeszenia-Dabrowska N, Mates D, Mukeria A, Holcatova I, Schmidt LS, Toro JR, Karami S, Hung R, Gerard GF, Linehan WM, Merino M, Zbar B, Boffetta P, Brennan P, Rothman N, Chow WH, Waldman FM and Moore LE: Improved identification of von Hippel-Lindau gene alterations in clear cell renal tumors. Clin Cancer Res 14(15): 4726-4734, 2008 . 
23 George DJ and Kaelin WG Jr.: The von Hippel-Lindau protein, vascular endothelial growth factor, and kidney cancer. N Engl J Med 349(5): 419-421, 2003.

24 Frew IJ and Moch H: A clearer view of the molecular complexity of clear cell renal cell carcinoma. Annu Rev Pathol 10: 263-289, 2015.

25 Akbani R, Ng PK, Werner HM, Shahmoradgoli M, Zhang F, Ju Z, Liu W, Yang JY, Yoshihara K, Li J, Ling S, Seviour EG, Ram PT, Minna JD, Diao L, Tong P, Heymach JV, Hill SM, Dondelinger F, Städler N, Byers LA, Meric-Bernstam F, Weinstein JN, Broom BM, Verhaak RG, Liang H, Mukherjee S, Lu Y and Mills GB: A pan-cancer proteomic perspective on The Cancer Genome Atlas. Nat Commun 5: 3887, 2014.

26 Jonasch E, Futreal PA, Davis IJ, Bailey ST, Kim WY, Brugarolas J, Giaccia AJ, Kurban G, Pause A, Frydman J, Zurita AJ, Rini BI, Sharma P, Atkins MB, Walker CL and Rathmell WK: State of the science: an update on renal cell carcinoma. Mol Cancer Res 10(7): 859-880, 2012.

27 Panka DJ, Mano T, Suhara T, Walsh K and Mier JW: Phosphatidylinositol 3-kinase/Akt activity regulates c-FLIP expression in tumor cells. J Biol Chem 276(10): 6893-6896. 2001.

28 Suhara T, Mano T, Oliveira BE and Walsh K: Phosphatidylinositol 3-kinase/Akt signaling controls endothelial cell sensitivity to Fasmediated apoptosis via regulation of FLICE-inhibitory protein (FLIP). Circ Res 89(1): 13-19, 2001.

29 Mashima T and Tsuruo T: Defects of the apoptotic pathway as therapeutic target against cancer. Drug Resist Updat 8(6): 339343, 2005.

30 Safa AR: Roles of c-FLIP in apoptosis, necroptosis, and autophagy. J Carcinog Mutagen 6: 003, 2013.

31 Kataoka T: The caspase-8 modulator c-FLIP. Crit Rev Immunol 25(1): 31-58, 2005.

32 Isono T, Chano T, Yoshida T, Kageyama S, Kawauchi A, Yonese $\mathrm{J}$ and Yuasa T: Abundance of TRAIL attenuated by HIF2 $\alpha$ and c-FLIP affects malignancy in renal cell carcinomas. Oncotarget 9(33): 23091-23101, 2018.

33 Shirley S and Micheau O: Targeting c-FLIP in cancer. Cancer Lett 332(2): 141-150, 2013.
34 Logan AE, Wilson TR, Fenning C, Cummins R, Kay E, Johnston $\mathrm{PG}$ and Longley DB: In vitro and in vivo characterisation of a novel c-FLIP-targeted antisense phosphorothioate oligonucleotide. Apoptosis 15(12): 1435-1443, 2010.

35 Johnson N and Shapiro GI: Cyclin-dependent kinases (cdks) and the DNA damage response: rationale for cdk inhibitorchemotherapy combinations as an anticancer strategy for solid tumors. Expert Opin Ther Targets 14(11): 1199-1212, 2010.

36 Senderowicz AM: Small-molecule cyclin-dependent kinase modulators. Oncogene 22(42): 6609-6620, 2003.

37 Dutto I, Tillhon M, Cazzalini O, Stivala LA and Prosperi E: Biology of the cell cycle inhibitor p21(CDKN1A): molecular mechanisms and relevance in chemical toxicology. Arch Toxicol 89(2): 155-178, 2015.

38 Mauro M, Rego MA, Boisvert RA, Esashi F, Cavallo F, Jasin M and Howlett NG: p21 promotes error-free replication-coupled DNA double-strand break repair. Nucleic Acids Res 40(17): 8348-8360, 2012.

39 Aguero MF, Facchinetti MM, Sheleg Z and Senderowicz AM: Phenoxodiol, a novel isoflavone, induces G1 arrest by specific loss in cyclin-dependent kinase 2 activity by p53-independent induction of p21 WAF1/CIP1. Cancer Res 65(8): 3364-3373, 2005.

40 Choueiri TK, Mekhail T, Hutson TE, Ganapathi R, Kelly GE and Bukowski RM: Phase I trial of phenoxodiol delivered by continuous intravenous infusion in patients with solid cancer. Ann Oncol 17(5): 860-865, 2006.

41 Howes JB, de Souza PL, West L, Huang LJ and Howes LG: Pharmacokinetics of phenoxodiol, a novel isoflavone, following intravenous administration to patients with advanced cancer. BMC Clin Pharmacol 11: 1, 2011.
Received August 6, 2018

Revised August 19, 2018

Accepted August 24, 2018 